\title{
Publisher Correction: Achilles' heel of antibiotic resistance
}

Anupama Khare

Correction to: Nature Microbiology https://doi.org/10.1038/s41564-021-00985-x, published online 25 October 2021.

In the version of this News \& Views initially published, a processing error led to the omission of an Acknowledgements section. The article has been amended to now include the following: "The author is supported by the Intramural Research Program of the NIH, National Cancer Institute (NCI), Center for Cancer Research."

The change has been made to the online version of the article.

Published online: 15 November 2021

https://doi.org/10.1038/s41564-021-01018-3

This is a U.S. government work and not under copyright protection in the U.S.; foreign copyright protection may apply 2021 